\title{
Aspectos clínicos e histológicos do granuloma piogênico: relato de caso
}

\section{Clinical and histological aspects of pyogenic granuloma: case report.}

\author{
Fabiano de Sant'Ana dos Santos ${ }^{1}$; Nicole Diello Salles ${ }^{2}$; Rhaysla Domingues ${ }^{2}$ \\ 1. Professor Doutor do Curso de Odontologia do Centro Universitário da Fundação Educacional de Barretos, \\ São Paulo. \\ 2. Acadêmicas do Curso de Odontologia do Centro Universitário da Fundação Educacional de Barretos, São Paulo.
}

\section{Resumo}

O granuloma piogênico é uma lesão inflamatória hiperplásica que pode se manifestar na gengiva. O objetivo deste estudo foi apresentar um relato de caso clínico de uma paciente que compareceu na Clínica do Curso de Odontologia do Centro Universitário de Barretos, São Paulo (UNIFEB), apresentando uma lesão sugestiva de granuloma piogênico. Após o preenchimento das formalidades inerentes ao prontuário da paciente, a mesma foi submetida aos exames físico e bucal, e, neste último, constatou-se a presença de uma lesão nodular, pediculada, coloração avermelhada e com sangramento presente, devido ao trauma. O diagnóstico clínico foi de granuloma piogênico e o diagnóstico diferencial foi realizado para lesão de células gigantes periféricas. Mediante consentimento da paciente, realizou-se uma biópsia excisional da lesão, a qual foi enviada para o Laboratório de Patologia do UNIFEB. O resultado da biópsia confirmou o diagnóstico clínico de granuloma piogênico, resultado que foi informado à paciente. A paciente foi encaminhada para tratamento periodontal básico e reabilitação bucal, visando à sua melhor qualidade de vida.

Palavras-chave: Granuloma piogênico, Diagnóstico, Estomatologia.

\begin{abstract}
The pyogenic granuloma is an inflammatory hyperplastic injury that can appear on the gums. The aim of this study was to present a case reported by a patient who attended the clinic of the University Center of Dentistry Course of Barretos, São Paulo (UNIFEB), presenting a lesion suggestive of pyogenic granuloma. After completing the formalities associated with the medical protocol of the patient, it was carried out the physical and dental examinations and in the latter it was found the presence of a nodular lesion, pedunculated, reddish and this bleeding due to trauma. The clinical diagnosis was pyogenic granuloma and differential diagnosis was made for peripheral giant cell injury. With the consent of the patient, there was an excisional biopsy of the lesion, which was sent to the UNIFEB pathology laboratory. The biopsy confirmed the clinical diagnosis of pyogenic granuloma, which was reported to the patient. The patient was referred for basic periodontal treatment and oral rehabilitation aiming at their better quality of life.
\end{abstract}

Keywords: Pyogenic Granuloma, Diagnosis, Oral medicine.

Autor para correspondência: Fabiano de Sant'Ana dos Santos Av. Prof. Roberto Frade Monte, 389 Aeroporto - Barretos, SP1 CEP: 14780-340 E-mail: fss@gmail.com | fss@uol.com.br Telefone: 33216411 | 17 98132-6963

Recebido em: 27/10/2015

Aceito para publicação em: 22/03/2016

https://doi.org/10.4322/1980-0029.182015 


\section{Introdução}

O granuloma piogênico é uma lesão proliferativa, na maioria das vezes, de origem traumática não neoplásica, é um crescimento comum na cavidade bucal semelhante a um tumor. É composto por tecido de granulação, vasos neoformados, células de defesa e fibroblastos (Krishnapillai et al., 2012; Kadeh et al., 2015). Geralmente, acomete a gengiva, em especial a papila interdental, localização que representa cerca de $70 \%$ dos casos, mas outros locais da boca também podem ocorrer com menos frequência (Amirchaghmaghi et al., 2008; Greenberg et al., 2008; Reddy et al., 2012). O granuloma piogênico em geral é único, a coloração varia de róseo a vermelho, dependendo do tempo da lesão e de maior ou menor grau de vascularização, seu tamanho é variável, é indolor e de fácil sangramento ao toque. Geralmente, as lesões mais antigas tendem a se tornar mais colagenizadas e de coloração rósea (Boraks, 2011).

O sexo feminino é mais afetado que o masculino, por conta dos efeitos vasculares provocados pelos hormônios femininos (Greenberg et al., 2008; Neville et al., 2012; Kadeh et al., 2015). Está presente em $5 \%$ das mulheres grávidas, por isso chamado também de granuloma gravídico. O granuloma piogênico não tem um agente etiológico específico, podendo estar associado com fator traumático de baixa intensidade agindo de modo prolongado e intermitente, frio ou calor intenso, alimentos ' afiados", próteses, deposição de cálculo, corpos estranhos, falta de higienização, entre outros (Greenberg et al., 2008; Boraks, 2011). $\mathrm{O}$ tratamento consiste na excisão cirúrgica local e a remoção incompleta pode levar à recidiva. O diagnóstico diferencial de outras lesões na mucosa, tais como granuloma de células gigantes, hemangiomas e Sarcoma de Kaposi, deve ser feito pela biópsia do tecido removido (Neville et al., 2012; Moraes et al., 2013).

Este estudo tem por objetivo apresentar um caso clínico de uma mulher com granuloma piogênico na mandíbula de origem traumática.

\section{Relato do caso - Descrição}

Paciente - 50 anos, gênero feminino, leucoderma - foi encaminhada à Clínica do Curso de Odontologia do Centro Universitário de Barretos (UNIFEB). A mesma foi atendida pela disciplina de Diagnóstico e Cirurgia, queixando-se do surgimento de um aumento volumétrico há cerca de 3 anos na região do elemento 46, o qual já havia sofrido exodontia. A paciente relatou não sentir dor no local, mas referiu insatisfação com sangramento presente, sempre pelos constantes traumas durante alimentação e escovação. Durante anamnese, a paciente relatou que já se encontrava na menopausa e estava sob tratamento endocrinológico para controle de hipotireoidismo. No exame clínico, foi observada uma lesão exofítica nodular globosa única emergindo da gengiva do rebordo alveolar inferior, na região interdental dos dentes 45 e 47 , com base pediculada, medindo $1,5 \times 1,2 \times 0,5 \mathrm{~cm}$, de coloração avermelhada, superfície irregular, de consistência firme e elástica, e levemente ulcerada (Figura 1). O diagnóstico clínico sugerido foi de granuloma piogênico. O diagnóstico diferencial foi lesão periférica de células gigantes. A paciente foi comunicada da lesão sugerida pelas características apresentadas e da importância da biópsia excisional, tendo consentido em sua remoção para análise histopatológica. Todo cuidado em termos de biossegurança foi realizado para o procedimento da biópsia. Ainda na mesma consulta, planejou-se a biópsia. A paciente recebeu anestesia local e, por meio de um bisturi (lâmina n. ${ }^{\circ} 15$ ), a lesão foi removida totalmente e armazenada em formol a $10 \%$, tendo sido a peça encaminhada para o Laboratório de Anatomia Patológica da UNIFEB (Figura 2). A paciente retornou para remoção da sutura, oportunidade em que se notou aspecto de cicatrização normal. A paciente foi orientada a manter a higienização bucal e foi agendado retorno em sete dias. A análise histopatológica revelou

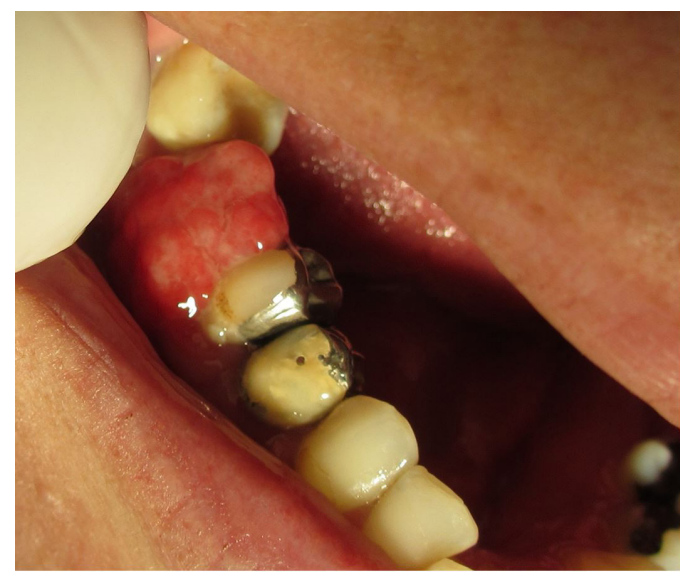

Figura 1. Granuloma piogênico localizado na gengiva distal do dente 45 . 


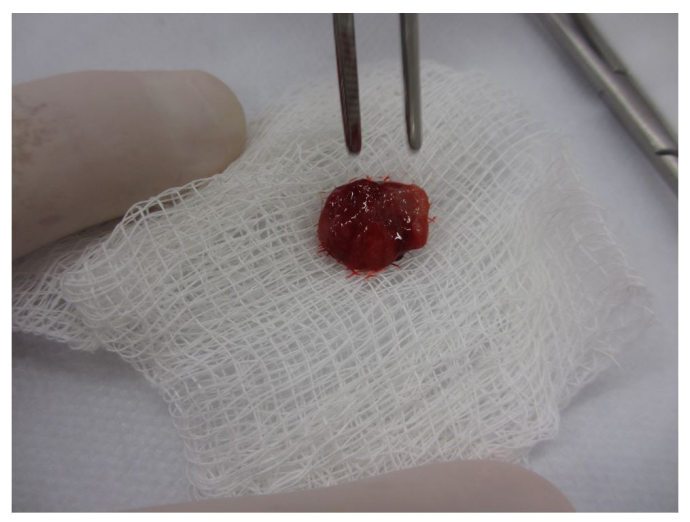

Figura 2. Excisão total do granuloma piogênico localizado na gengiva distal do dente 45 .

fragmentos de mucosa ulcerada com resíduo exudativo hemorrágico superficial sobre exuberante proliferação vascular, caracterizada por numerosos canais de calibre variado limitados por camadas de células endoteliais, estando, por vezes, carregados de sangue. Verificou-se presença de células inflamatórias (mononucleadas e polimorfonucleadas) adjacentes à área ulcerada. $\mathrm{O}$ laudo confirmou a hipótese de diagnóstico clínico sugerido - granuloma piogênico. No retorno, a paciente recebeu o diagnóstico da lesão benigna e foi encaminhada para clínica integrada para tratamento básico periodontal e reabilitação protética.

\section{Discussão}

No presente relato, a paciente enquadra-se no perfil para o desenvolvimento de granuloma piogênico, pois, de acordo com a literatura, esta lesão incide no sexo feminino a partir da quinta década de vida e, dentre as possíveis hipóteses sistêmicas para que isto ocorra, estão as variações dos hormônios (progesterona e testosterona), enquanto que, nos homens, a etiologia da lesão sugere estar associada ao diabetes (Neville et al., 2012; Gordón-Núñez et al., 2010; Kadeh et al., 2015). Um fato que chamou a atenção dos autores do presente relato de caso foi a paciente encontrar-se na menopausa e estar em tratamento para controle do hipotireoidismo. Nesta direção, a relação de desenvolvimento do granuloma piogênico associado às variações hormonais sexuais em mulheres de 50 a 59 anos já está bem elucidada. Entretanto, ao analisar a literatura sobre a associação entre o granuloma piogênico e o hipotireoidismo em estudos populacionais, não foram encontrados resultados que confirmassem tal relação (Saravana, 2009; Gordón-Núñez et al., 2010; Krishnapillai et al., 2012; Reddy et al., 2012; Maturana-Ramírez et al., 2015).

Neste estudo clínico, a lesão se localizava imediatamente na gengiva distal do dente 45 . Salienta-se que o referido dente apresentava-se com restauração, recessão gengival, acúmulo de placa bacteriana e cálculo subgengival; desta forma, conforme já está bem estabelecido na literatura, o aparecimento do granuloma piogênico está associado aos fatores locais citados (Greenberg et al., 2008; Boraks, 2011; Neville et al., 2012). De acordo com Saravana (2009), a etiologia e a patogênese da lesão devem ser conhecidas para compreender a sua natureza. Outro aspecto que também cabe análise é que este tipo de lesão tem predileção pela gengiva e $70 \%$ dos casos se manifestam nas papilas interdentais, sendo mais comuns na área anterior da maxila, quando comparada com qualquer outra área da cavidade bucal (Greenberg et al., 2008; Gordón-Núñez et al., 2010).

Sabe-se que o granuloma piogênico é uma lesão inflamatória, hiperplásica e benigna. Entretanto, no processo de diagnóstico, o cirurgião-dentista deve estar atento para diferenciar de outras lesões, como o Sarcoma de Kaposi, o melanoma amelanótico, o carcinoma de células escamosas, a lesão de células gigantes periféricas e o hemangioma (Amirchaghmaghi et al., 2008; Neville et al., 2012; Moraes et al., 2013). Assim, para confirmação do diagnóstico clínico, fez-se uma biópsia excisional e os operadores tiveram cuidado para remover toda a área de implantação do pedículo da lesão. Para evitar a recidiva da lesão, toda área acometida deve ser bem curetada, buscando remover todas as células do granuloma piogênico; além disto, os fatores irritantes também devem ser removidos (Greenberg et al., 2008; Saravana, 2009; Reddy et al., 2012). A lesão foi submetida à análise histopatológica, que confirmou o diagnóstico clínico de granuloma piogênico e este resultado foi comunicado à paciente.

Com relação ao aspecto histopatológico, o granuloma piogênico apresenta um tecido friável, hemorrágico e ulcerado. Há proliferação de tecido endotelial bem vascularizado e com pouco colágeno (Krishnapillai et al., 2012). Há presença de neutrófilos, células inflamatórias crônicas e formações de microabcessos por todo estroma edematoso (Greenberg et al. 2008; Boraks, 2011; Neville et al., 2012). Tal condição foi constatada 
no achado histopatológico do presente caso clínico relatado. Conhecido o diagnóstico da lesão, foi possível encaminhar a paciente para receber um tratamento adequado, buscando assim adequar sua condição de saúde bucal para evitar o surgimento de novas lesões hiperplásicas em sua cavidade bucal, conforme recomenda a literatura (Neville et al., 2012; Kadeh et al., 2015). Mais recentemente, há autores que estão realizando com segurança a terapia do granuloma piogênico com aplicação de laser (Frigerio; Tan, 2015). O tratamento não cirúrgico do granuloma piogênico também foi sugerido em um relato de caso, sendo que a principal justificativa foi o fato de esta lesão se recidivar após sua excisão cirúrgica clássica (Frumkin et al., 2015). Ainda sobre está última forma de tratar o granuloma piogênico, os autores do presente estudo entendem que estudos com seguimentos de mais casos devem ser realizados a fim de sacramentar tal técnica.

\section{Considerações finais}

O granuloma piogênico deve ser diagnosticado e tratado pelo cirurgião-dentista, buscando minimizar seus efeitos junto às estruturas de suporte dental, como a gengiva, o osso alveolar e demais áreas que esta lesão possa acometer. A remoção total da lesão e também dos fatores irritantes são determinantes para não haver a recidiva da lesão.

\section{Consentimento}

O Termo de Consentimento Livre e Esclarecido (TCLE) foi assinado pela paciente autorizando a publicação deste relato de caso e uma cópia da autorização escrita está disponível com o editor desta revista.

\section{Agradecimento}

Ao paciente pela sua contribuição no processo de aprendizagem dos alunos envolvidos neste estudo.

\section{Referências}

AMIRCHAGHMAGHI, M., FALAKI, F., MOHTASHAM, N., \& MOZAFARI, P. M. (2008). Extragingival pyogenic granuloma: a case report. Cases Journal, 1(371), 1-3.

BORAKS, S. Medicina bucal: tratamento clínicocirúrgico das doenças bucomaxilofaciais. São Paulo: Artes Médicas; 2011. 592p.
FRIGERIO, A., \& TAN, O. T. (2015). Laser applications for benign oral lesions. Lasers in Surgery and Medicine, 47(8), 643-650.

FRUMKIN, N., NASHEF, R., SHAPIRA, L., \& WILENSKY, A. (2015). Nonsurgical treatment of recurrent gingival pyogenic granuloma: a case report. Quintessence International, 46(6), 539-544.

GORDÓN-NÚÑEZ, M. A., DE VASCONCELOS CARVALHO, M., BENEVENUTO, T. G., LOPES, M. F., SILVA, L. M., \& GALVÃO, H. C. (2010). Oral pyogenic granuloma: a retrospective analysis of 293 cases in a Brazilian population. Journal of Oral and Maxillofacial Surgery, 68(9), 2185-2188.

GREENBERG, M. S., GLICK, M., \& SHIP, J. A. (2008). Burket's oral medicine (11th ed.). Hamilton: BC Decker Inc.

KADEH, H., SARAVANI, S., \& TAJIK, M. (2015). Reactive hyperplastic lesions of the oral cavity. Iranian Journal of Otorhinolaryngology, 27(79), 137-144.

KRISHNAPILLAI, R., PUNNOOSE, K., ANGADI, P. V., \& KONERU, A. (2012). Oral pyogenic granuloma -a review of 215 cases in a South Indian Teaching Hospital, Karnataka, over a period of 20 years. Oral and Maxillofacial Surgery, 16(3), 305-309.

MATURANA-RAMÍREZ,A.,ADORNO-FARÍAS, D., REYES-ROJAS, M., FARÍAS-VERGARA, M., \& AITKEN-SAAVEDRA, J. (2015). A retrospective analysis of reactive hyperplastic lesions of the oral cavity: study of 1149 cases diagnosed between 2000 and 2011, Chile. Acta Odontológica Latinoamericana, 28(2), 103-107.

MORAES, S. H., MORAES, G. F., DURSKI, J., VIERO, F. L., MEIRA, D. D. S., \& CARON, M. E. (2013). Granuloma piogênico: relato de caso clínico. Revista Gestão \& Saúde, 9(2), 12-19.

NEVILLE, B. W., DAMM, D. D., ALLEN, C. M. \& BOUGOUT, J. (2012). Oral and maxillofacial pathology (3rd ed.). Saint Louis: Saunders.

REDDY, V., SAXENA, S., SAXENA, S., \& REDDY, M. (2012). Reactive hyperplastic lesions of the oral cavity: a ten year observational study on North Indian Population. Journal of Clinical and Experimental Dentistry, 4(3), e136-e140.

SARAVANA, G. H. (2009). Oral pyogenic granuloma: a review of 137 cases. British Journal of Oral \& Maxillofacial Surgery, 47(4), 318-319. 